ISSN: $1412-8837$

\title{
KORELASI FAKTOR SOSIAL EKONOMI RUMAH TANGGA DENGAN TINGKAT PENUNGGAKAN PENGEMBALIAN KREDIT P4K DI KECAMATAN MUARA BANGKAHULU KOTA BENGKULU
}

\section{(Correlation Analysis Of Socio-Economic Household Factors To Delinquent Payment Level Of P4K Credit In Subdistrict Of Muara Bangkahulu, Bengkulu City)}

\author{
Musriyadi Nabiu, Reflis, Aswin \\ Jurusan Sosial Ekonomi Pertanian \\ Fakultas Pertanian Universitas Bengkulu
}

\begin{abstract}
This research is intended to study characteristics of $P 4 K$ creditors who are delinquent their credit payments, examine factors influencing their late P4K credit payments. From $40 \mathrm{P} 4 \mathrm{~K}$ creditors, only 23 creditors are able to accessed for this research and willing to participate. Rank spearman correlation and $t$-test methods are used to analyze the data gathered from respondents. The research finds that the level of family income and respondent' perception on rural development are highly correlated to the level of $P 4 K$ credit payment while number of family, working motivation and respondents perception on P4K program are not.

Key words: credit payment, socio-economic factors
\end{abstract}

\section{PENDAHULUAN}

\section{Latar Belakang}

Pembangunan nasional memiliki tujuan tercapainya masyarakat yang adil dan makmur yang merata material dan spiritual berdasarkan Pancasila dan Undang-Undang dasar 1945. Pemerintah berusaha meratakan pembangunan agar masyarakat benar-benar merasakan hasil pembangunan. Pelaksanaan pembangunan disamping meningkatkan pendapatan bagi seluruh rakyat Indonesia, sesuai dengan azas keadilan juga sekaligus mencegah melebarnya jurang pemisah antara yang kaya dan yang miskin. Penyebaran yang merata dari hasil pembangunan tersebut juga akan diwujudkan melalui kebijaksanaan yang serasi antara lain dibidang perkreditan perbankan.

Sebagian besar atau lebih dari $80 \%$ rakyat Indonesia hidup di daerah pedesaan. Dari sini jelaslah bahwa sektor pedesaan memang berperanan penting dalam kegiatan ekonomi dan produksi. Kegiatan-kegiatan ini umumnya berupa usaha pertanian serta kegiatan industri kecil dan rumah tangga serta kerajinan

12 | Musriyadi Nabiu, Reflis, Aswin. Analisis Faktor-Faktor yang Berhubungan dengan 
semua kegiatan ini melibatkan kegiatan perkreditan untuk produksi disamping itu juga terdapat banyak kegiatan perkreditan untuk tujuan konsumsi terutama karena tingkat pendapatan petani atau penduduk rendah.

Salah satu ciri umum yang melekat dalam masyarakat pertanian Indonesia adalah permodalan yang lemah. Kekurangan modal ini sangat membatasi ruang gerak aktivitas masyarakat pedesaan yang ditujukan untuk meningkatkan pendapatannya, sedangkan sumber dana dari luar yang bisa membantu mengatasi kekurangan modal sulit diperoleh telah membuat semakin sulitnya usaha-usaha untuk meningkatkan taraf hidup masyarakat pedesaan.

Taraf hidup masyarakat pedesaan pada umumnya masih relatif sangat rendah, disebabkan pendapatan dari sektor pertanian masih sangat kecil, maka ruang gerak mereka untuk memulai kegiatan usahanya sangat terbatas. Kalaupun memperoleh pinjaman modal sering kali terikat pada pemberian pinjaman gelap, dan pinjaman yang lebih tinggi dari pada bunga bank (tengkulak).

Fenomena lain yang cukup merisaukan adalah tingkat kemakmuran dan pendapatan yang rendah serta diiringi dengan kehidupan penduduk pedesaan yang banyak terlibat hutang pada lembaga kredit informal (Mubyarto: 1985). Penyediaan modal bagi anggota keluarga petani-nelayan miskin yang sebelumnya dibekali kemampuan mengembangkan usaha tertentu sudah tepat. Kalau tidak, kelompok pengangguran yang sangat kentara ini mengakibatkan kemiskinan absolut pada masyarakat petani-nelayan miskin.

Upaya yang dilaksanakan secara tidak langsung oleh IFAD atau ADB ini, dijembatani dalam sebuah proyek bernama Pembinaan Peningkatan Pendapatan Petani/nelayan Kecil (P4K). Proyek ini dikomandoi secara terpusat oleh Departemen Pertanian (Deptan) dengan mengandalkan para Penyuluh Pertanian Lapangan (PPL), untuk mencari solusi ekonomi berdasarkan karakteristik kemampauan dan potensi masing-masing daerah. Petugas Penyuluh kemudian berfungsi sebagai pembina kelompok usaha petani-nelayan kecil tersebut.

Pada tahun anggaran 1994-1995 dilakukan pengembangan lokasi P4K sebanyak 12 propinsi salah satu lokasinya adalah propinsi Bengkulu. Penyaluran kredit di Propinsi Bengkulu tersebut dilaksanakan di 4 Kecamatan Kota, salah satunya adalah Kecamatan Muara Bangkahulu yang tersebar di 5 kelurahan yang terdiri atas 94 RT. Kredit yang disalurkan sebanyak Rp 55.000.000,- di Kecamatan 
ISSN: $1412-8837$

Muara Bangkahulu ternyata memiliki tunggakan yang cukup besar, yaitu Rp 30.745.000,- yang tersebar dihampir seluruh kelurahan (Deptan, 2004).

Seperti diketahui bahwa keberhasilan kredit tidak hanya diukur dari peningkatan jumlah kredit yang disalurkan dan peningkatan hasil karena penggunaan kredit, tetapi penting juga melihat bagaimana kelancaran pengembalian kredit.

\section{Rumusan Masalah}

Berdasarkan latar belakang di atas, maka penelitian ini akan dilakukan untuk melihat faktor-faktor apa saja yang diduga berhubungan dengan tingkat penunggakan pengembalian kredit pada tingkat peserta petani proyek P4K, khususnya yang berada di Kecamatan Muara Bangkahulu kota Bengkulu.

\section{METODE PENELITIAN}

\section{Penentuan Lokasi}

Lokasi penelitian ini ditentukan secara sengaja (purposive), yaitu di kecamatan Muara Bangkahulu, dengan pertimbangan Kecamatan Muara Bangkahulu mengalami tunggakan yang cukup besar, dibandingkan dengan 4 Kecamatan lainnya di Kota Bengkulu seperti terlihat pada tabel 1 berikut.

Tabel 1. Penyebaran Kredit Berdasarkan Besar Tunggakan di 4 Kecamatan Kota

\begin{tabular}{clcccr}
\hline No & Kecamatan & $\begin{array}{c}\text { Tahun } \\
\text { Pengeluaran }\end{array}$ & $\begin{array}{c}\text { Jumlah } \\
\text { Kelompo } \\
\mathbf{k}\end{array}$ & $\begin{array}{c}\text { Jumlah } \\
\text { Tunggaka } \\
\mathbf{n}(\mathbf{R p})\end{array}$ & $\begin{array}{c}\text { Jumlah Kredit } \\
\text { (Rp) }\end{array}$ \\
\hline 1 & Gading & 2000 & 1 & $2.640,950$ & $6.000,000,-$ \\
2 & Cempaka & 2000 & 1 & 129,579 & $5.000,000,-$ \\
3 & Teluk Segara & 2000 & 2 & $2.950,000$ & $10.500,000,-$ \\
4 & Selebar & 2000 & 5 & $30.745,000$ & $50.000,000,-$ \\
& Muara & & & & \\
& Bangkahulu & & & $36.465,529$ & $71.000,000,-$ \\
\hline
\end{tabular}

Sumber : Laporan Bulanan Penanggung Jawab P4K, April 2004.

\section{Penentuan Responden}

Responden dalam penelitian ini adalah anggota peserta proyek P4K yang mengalami tunggakan dalam pengembalian kredit. Pengambilan responden dilakukan dengan metode Sensus. Menurut Singarimbun dan Efendi (1987), metode sensus yaitu pengambilan semua populasi yang ada didaerah penelitian. Populasi

14 | Musriyadi Nabiu, Reflis, Aswin. Analisis Faktor-Faktor yang Berhubungan dengan 
dalam penelitian ini, anggota dalam kelompok yang mengalami tunggakan pengembalian kredit berjumlah 40 orang yang tersebar di kelurahan dalam Kecamatan Muara Bangkahulu, dan semua populasi yang ada di jadikan sebagai responden.

\section{Pengumpulan Data}

Data dan informasi yang dikumpulkan pada penelitian ini, terdiri atas data primer dan data sekunder. Data primer diperoleh dari pengamatan dan wawancara langsung dengan responden dengan bantuan kuisioner, sedangkan data sekunder diperoleh dari instansi pemerintah serta berbagai pustaka yang berkaitan dengan penelitian ini.

\section{Analisis Data}

Untuk mengetahui hubungan variebel-variabel bebas dengan variabel terikat dilakukan dengan analisa Statistik Non Parametrik, yaitu uji korelasi Rank Spearman (rs). Menurut Siegel (1985), perhitungan koefisien korelasi rank Spearman (rs) tersebut dilakukan dengan rumus:

$$
r s=1-\frac{6 \sum_{i=1}^{n} d i^{2}}{N\left(N^{2}-N\right)}
$$

dimana :

rs : Koefisien korelasi rank Spearman

$\mathrm{N}$ : Jumlah responden (peserta penunggak kredit)

di : Selisih antara satu variabel pengaruh pada responden ke-i

i : Nomor responden $(1,2,3, \ldots \ldots, \mathrm{n})$

jika ada nilai sama (ties) maka faktor koreksinya ( $\mathrm{t}$ ) dimana = sebanyak observasi yang berangka sama, dengan rumus:

$$
t=\frac{t^{2}-t}{12}
$$


ISSN: $1412-8837$

sehingga rumus Rank Spearman menjadi:

$$
\begin{aligned}
r_{s} & =\frac{\sum X^{2}-\sum Y^{2}-\sum d i^{2}}{\sqrt[2]{\sum X^{2} \sum Y^{2}}} \\
\sum X^{2} & =\frac{N^{3}-N}{12}-\sum T x \\
\sum Y^{2} & =\frac{N^{3}-N}{12}-\sum T y
\end{aligned}
$$

dimana :

$\sum X^{2}=$ jumlahkuadratvar iabelbebas yang dikoreksi

$\sum Y^{2}=$ jumlahkuadratvar iabelterikat yang dikoreksi

$\sum T_{x}=$ jumlah faktorkoreksi var iabel bebas

$\sum T_{Y}=$ Jumlah faktor koreksi var iabel terikat

$N=$ Jumlah responden

X1 = Jumlah tanggungan keluarga (jiwa)

$\mathrm{X} 2$ = Tingkat pendapatan keluarga $(\mathrm{Rp})$

$\mathrm{X} 3$ = Frekuensi mengikuti pembinaan (skor)

$\mathrm{X} 4$ = Motivasi kerja (skor)

X5 = Persepsi petani terhadap P4K (skor)

Untuk menguji signifikansinya, maka digunakan uji $t$ hitung dengan formulasi sebgai berikut :

$$
t \text { hitung }=r s \sqrt{\frac{N-2}{1-r s^{2}}}
$$

Tingkat signifikansi yang digunakan 95\% ( $\alpha=0,05 \%)$ dengan kriteria pengujian sebagai berikut:

- Jika $t_{\text {hitung }}>t_{\text {tabel }}$ atau $-t_{\text {hitung }}<-t_{\text {tabel, }}$ maka H1 terima dan H0 ditolak. Variabel pengaruh yang diuji berhubungan nyata dengan tingkat penunggakan kredit.

16 Musriyadi Nabiu, Reflis, Aswin. Analisis Faktor-Faktor yang Berhubungan dengan 
- Jika $t_{\text {hitung }}<t_{\text {tabel }}$ atau $-t_{\text {hitung }}>-t_{\text {tabel }}$ maka tolak H1 dan terima H0, artinya variabel pengaruh yang diuji tidak berhubungan nyata dengan tingakat penunggakan kredit P4K.

\section{HASIL DAN PEMBAHASAN}

\section{Karakteristik Responden Penunggak Kredit}

Karakteristik responden penunggak kredit meliputi; umur, pendidikan, jumlah tanggungan keluarga, tingkat Pendapatan keluarga.

Tabel 7. Karakteristik Responden Penunggak Kredit

\begin{tabular}{cccc}
\hline \multicolumn{1}{c}{ U r a i a n } & Jumlah (Jiwa) & Persentase (\%) & Rata-rata \\
\hline Umur (Thn) & 13 & 33,5 & 39,5 \\
$>42$ & 13 & 33,5 & \\
$36-42$ & 14 & 35 & \\
$<36$ & & & 9,8 \\
Pendidikan (Thn) & 16 & 40 & \\
Tamat SLTP & 18 & 45 & \\
Tidak Tidak Tamat SLTP & 6 & 15 & \\
Tamat SD & 11 & & \\
Jumlah Tanggungan Keluarga & 17 & 42,5 & \\
$\quad>4,4$ & 12 & 30 & 687,888 \\
3,5 - 4,4 & & & \\
$<3,5$ & 13 & 32,5 & \\
Tingkat Pendapatan Keluarga & 17 & 47,5 & \\
$>$ 734,344 & 10 & 25 & \\
641,431 - 734,344 & & & \\
$<641,431$ & &
\end{tabular}

Sumber : Data Primer diolah, 2006.

\section{Umur}

Hasil penelitian pada Tabel 7 di atas, menunjukkan bahwa umur reponden penunggak proyek P4K di Kecamatan Muara Bangkahulu terbesar pada kisaran 31-50 tahun (32\%) dengan rata-rata 39,6 tahun. Tabel tersebut menunjukkan bahwa responden penunggak proyek $\mathrm{P} 4 \mathrm{~K}$ di daerah penelitian tergolong kedalam usia produktif, artinya responden penunggak proyek P4K di Kecamatan Muara Bangkahulu ini masih mempunyai kesempatan dan potensi yang besar untuk 
ISSN: $1412-8837$

meningkatkan penerimaan dari proyek P4K terutama pemanfaatan program perkreditan. Sejalan dengan penelitian Mutmainnah (1999), bahwa seseorang pada usia produktif akan memberikan hasil yang maksimal jika di bandingkan pada usia di bawah atau diatas usia produktif.

\section{Pendidikan}

Keberhasilan suatu usahatani dapat tercipta dengan adanya sumber daya manusia. Manusia merupakan faktor produksi yang sangat menentukan dalam pembangunan, oleh karena itu manusia memerlukan pendidikan salah satu sarana untuk memajukan masyarakat (Suhardiyono. L., 1997).

Tingkat pendidikan formal peserta penunggak kredit juga merupakan salah satu pendukung keberhasilan suatu usaha, dimana dengan semakin tingginya pendidikan, maka peserta akan lebih mudah menyerap pembahuruan atau teknologi dibidang pertanian. Tabel 7 diatas memperlihatkan bahwa responden penunggak proyek P4K (40\%) berpendidikan formal tamat SLTP, kategori sedang $45 \%$ dan kategori rendah atau tidak tamat SD sebanyak 15\%. Jadi dari tabel diatas dapat disimpulkan bahwa responden penunggak $\mathrm{P} 4 \mathrm{~K}$, pendidikannya masuk dalam kategori sedang atau rata-rata tamat SLTP. Ini suksesnya program wajib belajar 9 tahun oleh pemerintah, di Kecamatan Muara Bangkahulu.

\section{Jumlah Tanggungan Keluarga}

Responden penunggak P4K yang jumlah tanggungan keluarganya lebih banyak, tentunya harus berusaha lebih baik dan lebih giat dalam semua kegiatan, baik usahatani maupun usaha rumah tangga untuk memenuhi kebutuhan keluarganya. Tabel 7 di atas menggambarkan bahwa jumlah tanggungan keluarga responden penunggak kredit relatif tinggi (42,5\%) yang bekisar antara 3-5 orang dengan rata-rata jumlah tanggungan keluarga peserta penunggak adalah 4,0 orang. Semakin banyak jumlah tanggungan keluarga yang dimiliki, maka ini akan menjadi faktor penghambat dalam pengembalian kredit $\mathrm{P} 4 \mathrm{~K}$.

\section{Tingkat Pendapatan Keluarga}

Tabel 7 di atas menunjukkan bahwa tingkat pendapatan responden penunggak mempunyai kisaran Rp 550,000,- sampai dengan Rp 950,000,- perbulan. Responden yang memiliki kategori tingkat pendapatan sedang $(47,5 \%)$ dan masuk

18 | Musriyadi Nabiu, Reflis, Aswin. Analisis Faktor-Faktor yang Berhubungan dengan 
dalam kategori rendah. Rendahnya pendapatan peserta diakibatkan karena mereka mayoritas bermata pencaharian sebagai petani, dimana banyak faktor penghambat yang mempengaruhi mereka dalam menambah pendapatan, salah satu faktor tersebut adalah terus berkurangnya lahan pertanian, sehingga peserta penunggak kredit banyak yang beralih usaha pada mata pencaharian yang bersifat sementara atau lahan yang masih menyewa, sehingga pendapatan peserta menjadi rendah.

\section{Analisa Uji Korelasi}

Untuk mengetahui hubungan antara Faktor Independen (jumlah tanggungan keluarga, tingkat pendapatan keluarga, frekuensi mengikuti pembinaan, motivasi kerja, persepsi peserta terhadap P4K). dan Faktor dependen (tingkat penunggakan pengembalian kredit Proyek P4K) maka digunakan uji Korelasi Rank Spearman. Berikut ini tabel rekapitulasi perhitungan korelasi Rank Spearman.

Tabel 8. Hasil Perhitungan Uji Korelasi Rank Spearman, antara Faktor Independen dengan Faktor Dependen Peserta Proyek P4K di Kecamatan Muara Bangkahulu Kota Bengkulu.

\begin{tabular}{clccc}
\hline No & Faktor Independen & Rs & Rs $^{2}$ & T-hitung \\
\hline 1. & Jumlah Tanggungan Keluarga & $-0,447$ & 0,199809 & $-3,08037^{*}$ \\
2. & Tingkat Pendapatan Keluarga & $-0,732$ & 0,535824 & $-6,6231^{*}$ \\
3. & Frekuensi Mengikuti Pembinaan & $-0,892$ & 0,795664 & $-12,1642^{*}$ \\
4. & Motivasi Kerja & 0,071 & 0,005041 & 0,438781 \\
5. & Persepsi Peserta Terhadap P4K & 0,117 & 0,013689 & 0,726 \\
\hline
\end{tabular}

Sumber: Data Primer diolah, 2006 (Lampiran 11)

Keterangan *) Signifikan pada taraf kepercayaan 95\% ( $a=0,05)$ t-tabel $(0,25 ; n-2)= \pm 2,021$

\section{Jumlah Tanggungan Keluarga}

Dari hasil perhitungan uji Rank Spearman antara jumlah tanggungan keluarga (X1) dengan tingkat penunggakan Pengembalian kredit (Y) adalah -0,447, dengan nilai kuadrat $\left(\mathrm{rs}^{2}\right)$ sebesar 0,199809. Selanjutnya diketahui uji $\mathrm{t}$, bahwa jumlah tanggungan keluarga berhubungan nyata dengan penunggakan kredit. Dimana nilai $t$ hitung sebesar -3,08037 dan $t$ tabel -2,021 dengan taraf kepercayaan $95 \%$ atau (-t hitung < - t tabel). Hal ini disebabkan rata-rata anggota keluarga peserta 
ISSN: $1412-8837$

proyek P4K yang mempunyai pekerjaan untuk menambah pendapatan keluarga hanya satu orang.

Hal ini sesuai dengan penelitian Riniwati (1997), dimana jumlah tanggungan keluarga bepengaruh terhadap pengembalian kredit, karena jumlah tanggungan keluarga menentukan besar kecilnya pengeluaran rumah tangga.

\section{Tingkat Pendapatan Keluarga}

Hasil analisis Uji Rank Spearman diketahui bahwa besarnya rs antara tingkat pendapatan keluarga dengan tingkat pengembalian penunggakan kredit sebesar -0,732, serta $\mathrm{rs}^{2}$ sebesar 0,535824. Selanjutnya hasil uji t diketahui bahwa tingkat pendapatan keluarga berhubungan nyata dengan tingkat penunggakan kredit. Diketahui nilai $\mathrm{t}$ hitung sebesar -6,6231 lebih kecil dari nilai $\mathrm{t}$ tabel sebesar 2.021 atau (-t hitung < - t tabel) pada taraf kepercayaan 95\%.

Hal ini disebabkan karena dalam mengikuti kegiatan $\mathrm{P} 4 \mathrm{~K}$, peserta kurang mendapatkan pengetahuan dan wawasan sehingga peserta kurang bisa mencari dan memanfaatkan peluang yang ada untuk meningkatkan tingkat pendapatan keluarganya. Hal ini sejalan dengan pendapat Prawiranata (1994), bahwa penyebab lain adalah disebabkan mereka menjalankan usahanya dengan pengalaman yang didapat secara turun-temurun, tidak berusaha untuk memanfaatkan peluang yang ada karena keterbatasan pengetahuan dan wawasan. Di samping itu, banyak faktor yang mempengaruhi peserta dalam penglolaan usahanya antara lain faktor alam dan harga yang berfluktuasi, ini merupakan hambatan dalam mengembangkan usaha proyek $\mathrm{P} 4 \mathrm{~K}$.

Hal ini sesuai dengan penelitian Farial Hildalina (1997)., bahwa semakin tinggi tahapan pelaksanaan kredit $\mathrm{P} 4 \mathrm{~K}$, semakin rendah (kecil) pendapatan kelompok dari usaha yang dibiayai kredit P4K tersebut. KPK yang mampu memanfaatkan kredit lanjutan adalah KPK yang memiliki keragaan usaha yang baik. KPK tersebut kemudian akan (a) mampu mengembangkan usaha lain yang lebih menguntungkan, sehingga konsentrasi terhadap usaha yang dibantu KPK menurun, (b) menjadi sasaran program bantuan pengembangan usaha lain. Hal tersebut sejalan dengan kegiatan usaha $\mathrm{P} 4 \mathrm{~K}$ yang semakin kecil terhadap total pendapatan kelompok.

20 | Musriyadi Nabiu, Reflis, Aswin. Analisis Faktor-Faktor yang Berhubungan dengan 


\section{Frekuensi Mengikuti Pembinaan}

Hasil analisis statistik Uji Rank Spearman membuktikan hubungan antara frekuensi mengikuti pembinaan terhadap penunggakan pengembalian kredit berhubungan nyata, dimana nilai $t$ hitung sebesar $-12,1642$ lebih kecil dari nilai $t$ tabel sebesar -2,021 (-t hitung < -t tabel). Hasil perhitungan ini tidak sesuai dengan yang diharapkan oleh pihak manajemen $\mathrm{P} 4 \mathrm{~K}$, bahwa dengan adanya pembinaan diharapkan usaha yang dijalankan dari kredit yang kucurkan bisa berkembang, namun pada kenyataanya peserta P4K justru banyak yang menunggak. Hal ini disebabkan (1) Kurangnya manajemen keuangan usaha responden penunggak P4K, (2) Rata-rata tingkat kesadaran responden penunggak P4K dalam mengikuti pembinaan masih sangat kurang, (3) Rata-rata tingkat pendidikan responden penunggak P4K rendah.

Ini sesuai dengan penelitian Farial Hildalina (1997.), bahwa tingkat pengetahuan para KPK dalam mengelola usahannya sangat berpengaruh, dan kurangnya pengetahuan dalam mengelola usahanya membawa konsekuensi pada keterlambatan angsuran kredit yang pada akhirnya menimbulkan tunggakan terhadap cicilan pengembalian kredit.

\section{Motivasi Kerja}

Diketahui besarnya rs antara Motivasi kerja dengan tingkat penunggakan pengembalian kredit adalah sebesar 0,071 dengan nilai kuadrat rs ${ }^{2}$ sebesar 0,005041. Selanjutnya hasil uji signifikansi dengan menggunakan uji $\mathrm{t}$ diketahui bahwa motivasi kerja tidak berhubungan nyata dengan tingkat penunggakan pengemablian kredit, dimana nilai nilai $t$ hitung sebesar 0,438781 lebih kecil dari $t$ tabel sebesar 2,021 ( $t$ hitung $<t$ tabel), pada taraf kepercayaan 95\%. Dengan demikian hasil penelitian ini tidak mendukung hipotesis penelitian yaitu motivasi kerja memiliki hubungan yang nyata dengan tingkat penunggakan pengembalian kredit.

Berdasarkan hasil peneltian ini, dapat diketahui bahwa motivasi kerja peserta P4K menjamin peserta sadar dalam mencicil penunggakan pengembalian kredit. Ini berarti setiap satu satuan peningkatan maupun penurunan nilai motivasi kerja, tidak mempengaruhi peserta P4K untuk melakukan tunggakan kreditnya.

Hasil penelitian ini bertentangan dengan pendapat Gerungan (1983), yang menyatakan bahwa, motivasi yang memberikan penggerak, alasan atau dorongan- 
ISSN: $1412-8837$

dorongan dalam diri manusia yang menyebabkan ia berbuat sesuatu. Dorongan yang timbul dari dalam diri manusia tersebut adalah dorongan untuk memenuhi kebutuhan hidupnya, untuk memenuhi kebutuhan hidupnya maka petani perlu melakukan sesuatu agar produksi usahanya meningkat sehingga penerimaan yang diperolehnya juga akan meningkat, semakin besar jumlah penerimaan yang diperoleh dari usahatani maka semakin besar kesempatan untuk melunasi pinjamannya.

\section{Persepsi Peserta Terhadap P4K}

Besarnya rs antara persepsi peserta terhadap P4K dengan tingkat penunggakan pengembalian kredit adalah sebesar 0,117 dengan nilai rs $^{2}$ sebesar 0,013689. Selanjunya dianalisa dengan menggunakan Uji Korelasi Rank Spearman, hasil uji signifikasi dengan menggunakan uji t diketahui bahwa persepsi peserta terhadap $\mathrm{P} 4 \mathrm{~K}$ tidak berhubungan nyata dengan tingkat penunggakan pengembalian kredit, dimana nilai $t$ hitung 0,726 lebih kecil dari nilai $t$ tabel sebesar 2,021 ( $t$ hitung $<t$ tabel) dengan taraf kepercayaan 95\%. Dengan demikian hasil penelitian ini tidak mendukung hipotesa penelitian yaitu persepsi peserta terhadap P4K berhubungan nyata dengan tingkat penunggakan pengembalian kredit.

Tidak adanya hubungan yang nyata antara persepsi peserta terhadap tingkat penunggakan kredit, ini disebabkan karena selama ini baik peserta P4K maupun pihak manajemen kredit berusaha agar pengembalian kredit, khususnya tingkat penunggakannya diharapkan bisa ditekan sekecil mungkin.

\section{SIMPULAN DAN SARAN}

\section{Kesimpulan}

Berdasarkan hasil penelitian dan analisis data maka dapat diambil beberapa kesimpulan, anatara lain:

1. Karakteristik responden penunggak kredit $\mathrm{P} 4 \mathrm{~K}$ adalah :

Umur peserta proyek $\mathrm{P} 4 \mathrm{~K}$ di daerah penelitian tergolong kedalam usia produktif. Pendidikan peserta P4K tergolong kedalam kategori sedang atau rata-rata tamat SLTP. Kemudian Jumlah Tanggungan Keluarga peserta P4K rata-rata berjumlah 4,0 orang (jiwa). Serta Tingkat Pendapatan Keluarga peserta P4K mempunyai kisaran Rp 550,000,- s/d Rp.950,000,- perbulan dan masuk dalam kategori rendah.

22 | Musriyadi Nabiu, Reflis, Aswin. Analisis Faktor-Faktor yang Berhubungan dengan 
2. Jumlah tanggungan keluarga, tingkat pendapatan keluarga, frekuensi mengikuti pembinaan berhubungan nyata dengan penunggakan kredit, tetapi persepsi dan motivasi kerja peserta terhadap P4K tidak berhubungan nyata dengan tingkat penunggakan

\section{Saran}

Diharapkan kepada seluruh KPK proyek P4K di Kecamatan Muara Bangkahulu memiliki kesadaran untuk mencicil tunggakan kredit. Serta kepada pihak manajemen P4K untuk lebih giat lagi dalam memberikan arahan agar tujuan proyek P4K tercapai.

\section{DAFTAR PUSTAKA}

Deptan 2004. Peta Sebaran Tunggakan Kredit KPK Kota Bengkulu 1 April 2004. Bengkulu.

Farial, Hildalina, 1997. Analisa Faktor-faktor yang Mempengaruhi Kelancaran Pengembalian Kredit Investasi Untuk Tani Kelapa Hibrida pada Proyek TCSDP (Tree Crop Smallholder Deploment Project) Propinsi Lampung. Jurusan Sosial Ekonomi Pertanian Universitas Lampung. Jurnal Penelitian. Vol IX. No8. Agustus 1997 UniversitasLampung.

Mubyarto, W.A, 1985. Pengantar Ekonomi Pertanian. Balai Pustaka. Jakarta.

Riniwati, N. Harahaf, 1997. Evaluasi Kredit Informasi Terhadap Usaha Penangkapan Ikan dan Komsumsi Rumah Tangga Nelayan dalam Upaya Memperbaiki Sistem Perkreditan di Desa Pantai Pasuruan, Jawa Timur, Agro Ekonomi Vol. 9 No. 2 Hal 57-66.

Singarimbun, M dan Efendi. 1987. Metode Penelitian Sosial. Cetakan ke-7. LP3ES. Jakarta. 